\title{
Gran tumor suprarrenal
}

\author{
J. I. Rodríguez-Hermosa, J. Roig, P. Ortuño ${ }^{1}$, A. M. Quiles ${ }^{1}$, M. Recasens ${ }^{2}$ y A. Codina-Cazador \\ Servicios de Cirugía General y Digestiva, ${ }^{1}$ Radiodiagnóstico y ${ }^{2}$ Endocrinología. Hospital Universitario Dr. Josep Trueta. \\ Girona
}

\section{INTRODUCCIÓN}

Aunque la cirugía laparoscópica de órganos sólidos ha tardado en implantarse más tiempo que la de las vísceras huecas, principalmente por el problema de la hemostasia y por su extracción, la adrenalectomía laparoscópica es en la actualidad la técnica de elección en el tratamiento de la enfermedad adrenal benigna (1); y podría llegar a ser el tratamiento de elección de los tumores adrenales malignos $(2,3)$.

\section{CASO CLÍNICO}

Varón de 58 años con antecedentes de hipertensión arterial, insuficiencia renal crónica, quistes renales bilaterales, hemorragia digestiva alta por úlcera duodenal, dislipemia, obesidad tipo I (índice de masa corporal $33,4 \mathrm{~kg} / \mathrm{m}^{2}$ ) e interveni-

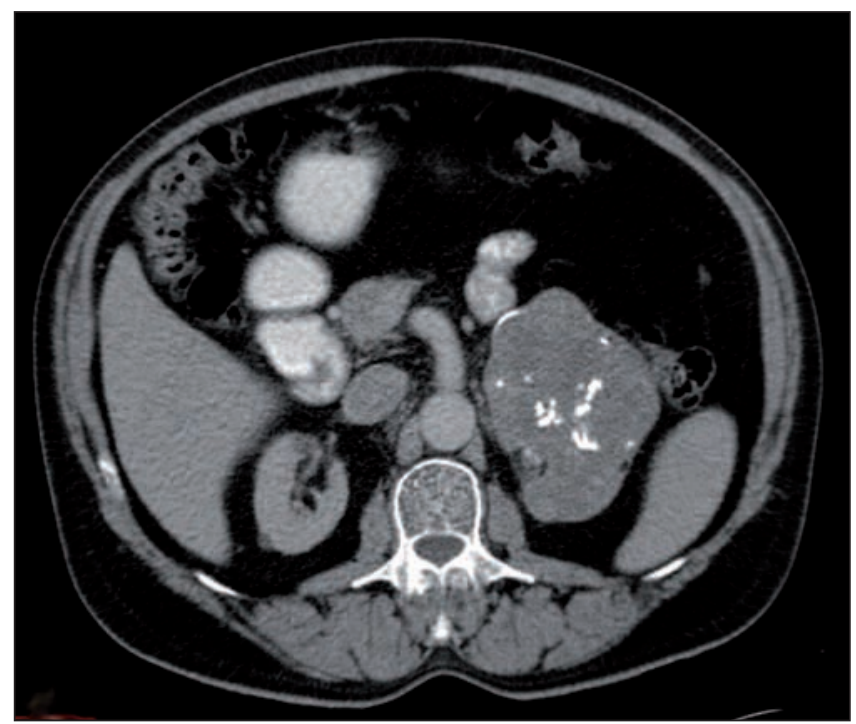

Fig. 1. Tomografía computerizada abdominal, proyección axial: gran masa adrenal izquierda, parcialmente calcificada.

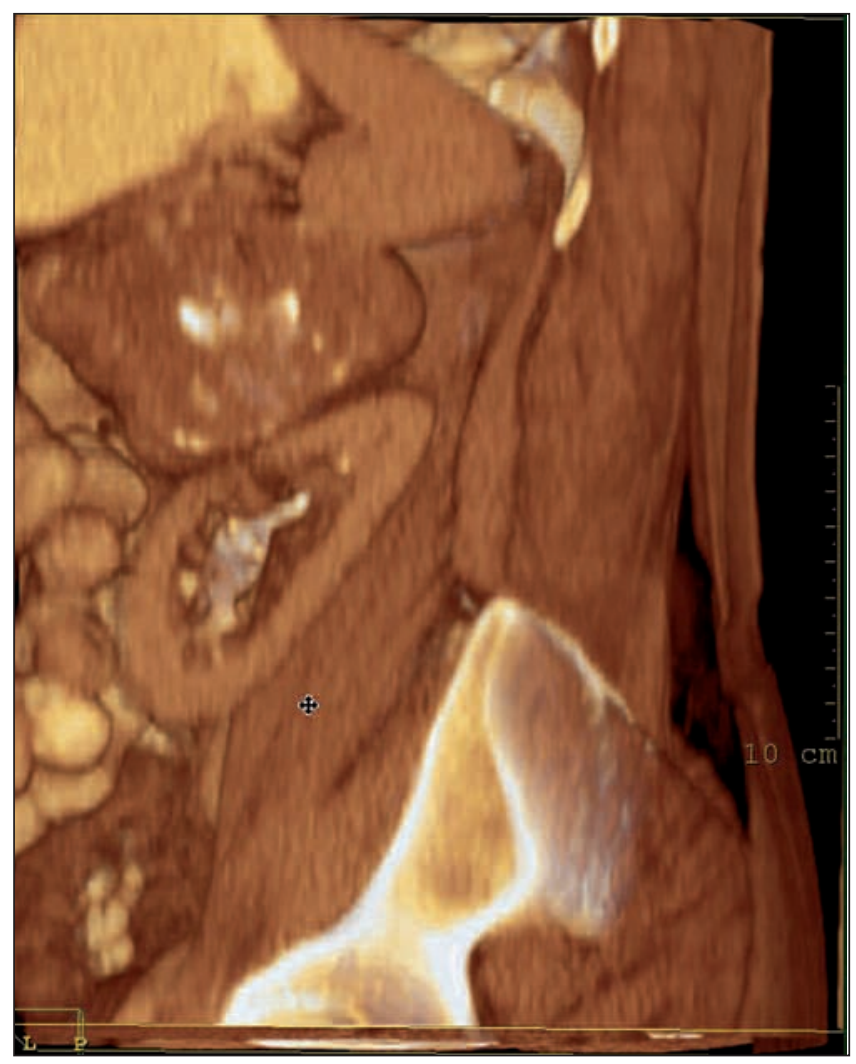

Fig. 2. Reconstrucción tomográfica abdominal 4D, proyección sagital: gran tumoración adrenal izquierda. 


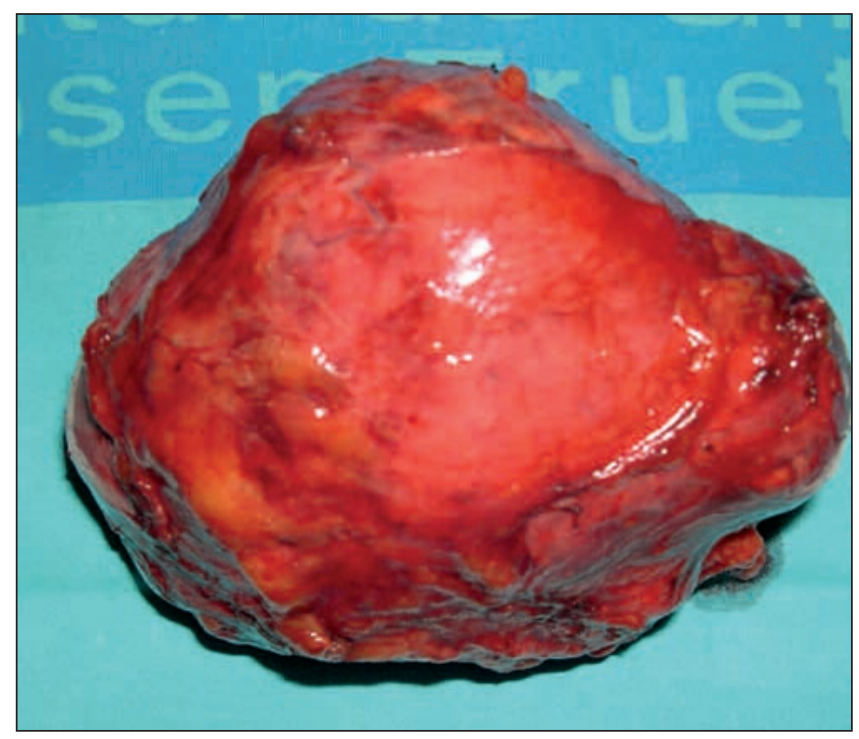

Fig. 3. Pieza quirúrgica: adenoma cortical suprarrenal, con extensas áreas de necrosis hemorrágica, hialinización y focos de calcificación. do de prolactinoma. Presenta una tumoración suprarrenal izquierda no funcionante de gran tamaño, diagnosticada por TC abdominal (Figs. 1 y 2). Se efectuó un abordaje laparoscópico, con liberación del ángulo esplénico del colon y movilización medial espleno-pancreática; sección de la vena principal adrenal izquierda y de los vasos accesorios venosos y arteriales; exéresis completa de la glándula adrenal tumoral, revisión de la hemostasia y extracción de la pieza en una bolsa preformada a través de una minilaparotomía transversa. El estudio histológico de la pieza evidenció una lesión de carácter heterogéneo, con áreas hemorrágicas, áreas de coloración parduzcas, áreas amarillentas y extensas áreas de necrosis hemorrágicas; también se identificaron septos con focos de calcificación. El diagnóstico definitivo fue de adenoma cortical suprarrenal $(14 \times 12 \times$ $11,5 \mathrm{~cm}$ de diámetro) (Fig. 3). El paciente fue dado de alta al tercer día sin complicaciones.

\section{DISCUSIÓN}

En términos generales, en la cirugía adrenal se recomienda no realizar un abordaje laparoscópico en lesiones con un tamaño superior a $10 \mathrm{~cm}$ de diámetro, a causa de las dificultades técnicas y por la posibilidad de malignidad (2), pero en nuestra serie -con 30 adrenalectomías laparoscópicas en los últimos 4,5 años- se extirparon cuatro adrenales con 10, 10, 12 y $14 \mathrm{~cm}$ de diámetro respectivamente, sin complicaciones. Pocos artículos describen una resección laparoscópica de masas adrenales mayores de $14-15 \mathrm{~cm}(4)$.

Para Gagner, precursor de la adrenalectomía laparoscópica en 1992, las limitaciones de la laparoscopia son dependientes de la experiencia del cirujano y no de las técnicas mínimamente invasivas (3).

Presenta los beneficios de la cirugía mínimamente invasiva, respecto a la técnica abierta, como son la mínima morbilidad, la menor necesidad de analgésicos, la reducción de la estancia hospitalaria y de la convalecencia (1).

\section{BIBLIOGRAFÍA}

1. Ruiz-Tovar J, Pérez J, Alonso N, Díez M, Rojo R, Collado MV, et al. Adrenalectomía laparoscópica. Cir Esp 2007; 82: 161-5.

2. Assalia A, Gagner M. Laparoscopic adrenalectomy. Br J Surg 2004; 91: 1259-74.

3. Gumbs AA, Gagner M. Laparoscopic adrenalectomy. Best Pract Res Clin Endocrinol Metab 2006; 20: 483-99.

4. O’Boyle CJ, Kapadia CR, Sedman PC, Brough WA, Royston CM. Laparoscopic transperitoneal adrenalectomy. Surg Endosc 2003; 17: 1905-9. 